\title{
Erftes Dorwort.
}

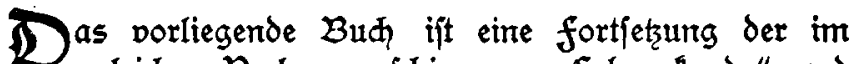
gleiden Derlage erihienenen "Sebensfunde" und ift für geiftig mündige junge Eeate beiderlei Gefale le ts beftimmt. Einige 2lusführungen aus der "Jugendlehre" fowie aus anderen Sdriften des $\mathcal{D e r}$ faffers jind mitaufgenommen worden, weil fie für den Jweet des Budhes bejonders geeignet erfdienen.



Der Derfaffer.

\section{Jwoeites Dorwort.}

Die vorliegende neue Uusgabe der "Iebensführung" hat eine ganje Reihe von Jెufäłzen erhalten, u. a. die Kapitel "Charafter und Schiffal", "Jur Ethif des familienlebens", "Der Whenf und das Geld", "Gee wiffensfragen", "Soziale Kultur". Zuah in die.anderen Kapitel find perjhiedene neue Betrahtungen eingefügt worden. Zuf Grund diejer Erweiterungen wendet fid


Sente berücfichtigt, an denfende Menidhen überhaupt

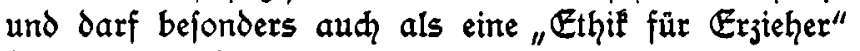
betraditet werden.

Zürid, den 1. Lcopember 1911.

Der $\mathcal{D e r f a f f e r}$. 